\title{
ANGINA PECTORIS FOLLOWING A CRUSHING ACCIDENT
}

\author{
BY \\ MAURICE CAMPBELL \\ From the National Hospital for Diseases of the Heart
}

Received January 27, 1939.

Trauma, it is generally agreed, plays an unimportant part in the ætiology of heart disease, but occasionally, as in the preceding paper by O'Farrell (1939), an injury provides an interesting and unusual problem. In the case that follows, the absence of any electrocardiograms soon after the accident makes the evidence incomplete, but it is the best instance seen by the writer of an injury producing a picture very similar to that of a cardiac infarct.

A man of 47 years felt very fit and was able to do heavy work as a furnitureremover without any symptoms; he had actually won a race of a hundred yards at some local sports four years before although he then weighed 14 stone. He gave no history of any previous illnesses.

One afternoon when he was unloading furniture, a fireplace surround weighing 3 cwt. slipped from the van and fell against his chest. It struck him just to the left of the mid line, inside and above the apex beat, and pushed him backwards, but a wall behind him prevented him from falling. He was imprisoned in this position for five or ten minutes, crushed between the wall and the fireplace surround. The pain was not severe; in fact, he said that he felt nothing that could really be called pain. When he was released he felt shocked and shaky; he sat down and rested for an hour, but still does not remember feeling any special pain. It was then an hour before work finished for the day, and he carried on for this time feeling fairly all right, but naturally not doing anything heavy.

When he had finished work and locked up, two hours after the accident, he started to walk home. After about 200 yards he had very acute pain in the middle of the sternum, which immediately made him stop until it passed off. This was the first real pain he had experienced, and it was accompanied by dyspnœa ; it recurred five or six times on his way home. He tried to do some work the next few days but could hardly do anything, and the pain got worse, i.e. more easily provoked, even on walking about slowly. After four days it seemed as bad as ever, so his doctor sent him to bed for two weeks. There had been no attack of pain that was outstanding in its length or severity, but all were very severe and he could hardly say if they were worse the first evening or during the next four days. This rest at once stopped the attacks of pain, but 
they returned again when he started to get up and about. He was sent to hospital and was advised to rest for three months ; he did not have an X-ray examination, but there seems to have been nothing to suggest a fractured rib. He spent this three months quietly at home and was free from. pain so long as he did not try to do much.

He was first seen by me at the National Hospital for Diseases of the Heart in October 1932, four months after the accident. He felt he was improving, but complained that on any exertion, especially on walking quickly, he had a sharp pain, which started near the left costal margin, passed up the middle of the sternum to the throat, and made him stop until relief came in two or three minutes. There was some dyspnœa with the pain, but both were less severe than at first. The cardio-vascular system cannot have been normal before his accident, as the aorta was rather widened and atheromatous and the retinal arteries were thickened ; the heart was probably a little enlarged, the maximum transverse diameter being $12.5 \mathrm{~cm}$. in a chest of $24.5 \mathrm{~cm}$., although its rather horizontal position made the determination of slight enlargement difficult. The only other abnormal physical signs found were a blood pressure of $150 / 100$ $\mathrm{mm}$. and an electrocardiogram showing a flat T 2 and a slightly inverted $\mathrm{T} 3$.
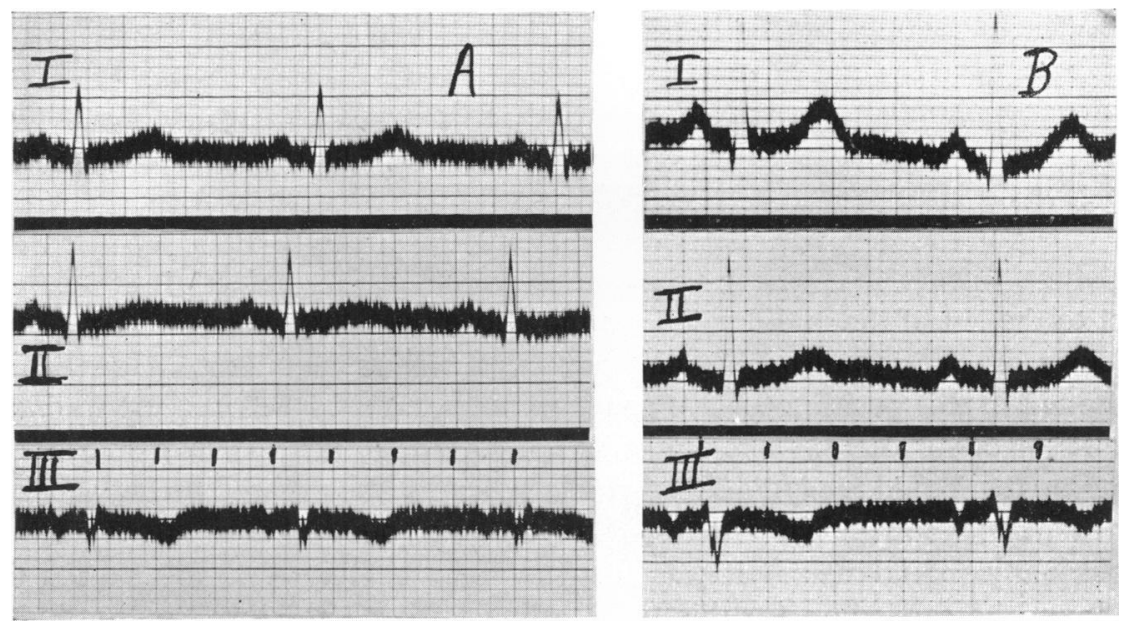

FIG. 1.-Electrocardiograms taken (A) four months and (B) five years after the accident. The improvement in the $T$ waves, in spite of the heart having increased in size, suggests that the $T$ waves may have been even flatter or inverted just after the accident.

After six weeks he was allowed to resume light work, as though the pain still returned if he exerted himself too much, he felt quite well when he did not do anything strenuous. The blood pressure, which had been $150 / 100 \mathrm{~mm}$., had fallen to $130 / 90 \mathrm{~mm}$., so probably some of the rise on the first occasion was temporary and due to excitement. He was fortunately an old and valued servant of the firm, so was given very easy work wrapping up and despatching parcels.

He was not seen again till 1937-after an interval of five years. He felt all right if he led a quiet life, but still got pain on any exertion. This started in the 
epigastrium and passed up to the throat with a sensation of choking and made him stop, until it had passed off after he had rested for a few minutes. The pain was more likely to come on walking than at work; but ever since the accident he had continued to do the same easy work, which did not involve any heavy exertion. On examination his heart had increased $2 \mathrm{~cm}$. in size to $14.5 \mathrm{~cm}$., but the increase in weight, from thirteen to fourteen and a half stone, might have been partly responsible. The second sound was accentuated in the aorta area, and the blood pressure was 160/100-105 mm., a little higher than in 1932. His electrocardiogram showed large upright $\mathrm{T}$ waves in leads I and II, with some inversion of $\mathrm{T}$ in lead III. It is unfortunate that no complete series of curves had been taken in the first few weeks after the accident, as they might have proved the presence or absence of an actual infarct ; but in 1932, four months after his accident, $\mathrm{T}$ in lead II had been almost flat and $\mathrm{T}$ in lead $\mathrm{I}$ smaller, so it seems likely that there had been earlier changes similar to those found after cardiac infarction.

At this stage the case was taken to court under the Workmen's Compensation Act and he was awarded $£ 500$ and additional payment for the time he had been off work; he was allowed to continue the light work he had been performing for five years. The opinion expressed by the writer was that an actual thrombosis in a coronary artery or other localized damage in the heart muscle had resulted from the accident and within a short time of it; and that his anginal pain was due to this cause. It was admitted that his cardiovascular system might not have been normal before the accident, but he had been able to do heavy work without any cardiac symptoms.

After another two years (1939) his condition has not changed greatly. The T waves in his electrocardiogram have become a little flatter, though perhaps the pain is less easily provoked. He is still doing the same easy work. There has been no further increase in the size of his heart.

Barber (1938) has reported twenty instances of heart disease that he attributes to trauma or strain, seen in the course of thirty years' practice. In two of these, both elderly men, anginal pain followed an injury; one had a fracture of the sternum where he was struck by the shaft of a cart, and the other had bruised his ribs from jumping on a moving cart. Both had to rest after the accident and the anginal pain was first noticed when they started walking three and two weeks respectively after their accidents. It is not clear how long the pain persisted. He quotes a third example reported by Fraser (1929).

\section{SUMMARY}

A man who was leading an active life and doing heavy manual work without any cardiac symptoms, developed sternal pain within two hours of a crushing accident ; and this pain continued afterwards and was associated with some progressive increase in the size of his heart. There seems no doubt that the actual damage done to the heart at the time he was crushed was responsible for these symptoms and signs. 
The commonest severe injury to the heart in crushing accidents is rupture of muscle fibres, sometimes through the whole thickness of the muscle wall; and in this case rupture of muscle fibres and extravasation of blood might account for all that was found without an actual thrombosis. But the fact that typical anginal pain, which he had never experienced before, occurred so soon and persisted for so long after the accident makes it likely that an actual thrombosis was produced while he was imprisoned, and that as soon as he started to walk after this he felt anginal pain. Alternatively, an injury or contusion of the artery at the time he was crushed might have been followed by an actual thrombosis two hours later, when he first felt severe pain. In either case, his symptoms were just those that would be expected after a cardiac infarct, and he seemed to have been in perfect health up to the time of the accident.

\section{REFERENCES}

Barber, H. (1938). Brit. med. J., 1, 433.

Fraser, A. J. (1929). Trauma, Disease, and Compensation, London, 106 ; quoted by Barber (1938).

O'Farrell, P. T. (1939). Brit. Heart J., 1, 172. 